\title{
O PRODUTO COMO CAUSADOR DE ACIDENTES
}

\author{
Widomar Pereira Carpes Junior, Dr. Eng. \\ Departamento de Metal-Mecânica, Centro Federal de Educação Tecnológica, \\ Florianópolis, Santa Catarina, Brasil \\ Ingeborg Sell, Dr. rer.nat. \\ Engenharia de Produção, Universidade Regional de Blumenau, \\ Blumenau, Santa Catarina, Brasil
}

Keywords: Accidents; Product Safety Analysis; Hazardous Products.

Palavras-chave: Acidentes; Análise da Segurança do Produto; Produtos Perigosos.

Neste artigo analisa-se a contribuição dos produtos para a geração de acidentes, apresentando-se estatísticas de acidentes de trabalho, de trânsito e aeronáuticos. Além disso, para melhor ilustrar a relação entre produtos e a ocorrência de acidentes, alguns casos de acidentes ocorridos e divulgados pela mídia são comentados. As estatísticas e os casos comentados demonstram a importância do estudo dos acidentes envolvendo produtos, evidenciando que praticamente todos os acidentes estão relacionados com o uso de produtos industrializados. Então, se analisa histórica e criticamente as principais teorias de acidentes de trabalho, porque são as únicas teorias existentes em relação aos acidentes. Além delas, são analisados os diversos conceitos sobre o erro humano e sua ocorrência, pois estes são apontados como grandes causadores de acidentes. Nesta análise, se observa que os acidentes estão mais relacionados aos perigos ou às características perigosas dos produtos do que às atitudes e ao comportamento do usuário. Faz-se uma revisão dos conceitos associados aos acidentes, tais como perigo, risco, acidente e dano, a partir dos quais apresenta-se um fluxograma contendo os elementos necessários para a manifestação dos acidentes.

Ao final, conclui-se que a participação dos produtos na ocorrência de acidentes é evidente e que o comportamento do usuário é dependente das características do produto e da situação na qual ele é utilizado.

In this paper, the contribution of products to the accidents occurrence was studied. With this purpose, statistics of work, traffic and aeronautical accidents were 
analysed. Some published cases of accidents were reviewed to illustrate the relationship between products and accidents. Also, several theories about work accidents were studied wich point human error as the main cause of accidents. In spite those theories, in this work it was observed that accidents are most related to hazardous characteristics of products than to user's acts or behavior. The review of concepts associated to accidents, such as hazard, risk, accident and damage, allowed to related the necessary elements for accidents occurrence. Finally, it was concluded that products characteristics and it's use conditions determine the user's behavior and the probability of accidents occurrence.

\section{INTRODUÇÃO}

Desde o início da sua existência, o ser humano busca transformar a natureza para melhor atingir seus objetivos ou executar tarefas. Nesta transformação da natureza foram gerados produtos, hoje fabricados em quantidades expressivas.

A partir do século XX, iniciou-se a sistematização da concepção de produtos, com o surgimento de metodologias de projeto de produtos. Elas propiciam que o produto cumpra sua função da melhor forma possível (boa funcionalidade) e tenham custos e tempo de produção reduzidos. Porém, muitos produtos, mesmo os mais eficientes, oferecem perigos aos usuários expondo-os a riscos. Devido às condições de uso ou condições ambientais adversas, esses riscos podem vir a resultar em eventos indesejados, como acidentes. Um acidente pode ocasionar lesões, mortes, processos judiciais, danos materiais diversos, e é no ambiente próximo do produto que se busca "o culpado", atribuindo-se a culpa ao usuário. Porém, negligencia-se que a desconsideração da grande variabilidade existente entre as capacidades, habilidades, aptidões e limitações das pessoas no desenvolvimento de produtos é fundamental para a ocorrência de acidentes.

\section{ACIDENTES COM PRODUTOS}

Para verificar a importância da segurança na utilização de produtos, convém analisar alguns dados estatísticos de acidentes que denotam, sobretudo, as conseqüências da falta dela. As estatísticas de acidentes do trabalho no Brasil são alarmantes: aproximadamente 50.000 trabalhadores morreram entre 1978 e 1988 
devido a acidentes do trabalho; em 1991, o Brasil ocupava o $10^{\circ}$ lugar no ranking de acidentes do trabalho (OIT, 1993).

Em nível nacional, infelizmente, não há estatísticas relacionando os acidente aos produtos. No Estado de Santa Catarina há dados que associam acidentes do trabalho a objetos causadores (Tab. 1), sendo estes objetos, em sua maioria, equipamentos ou partes deles ou ainda materiais, enfim produtos industrializados.

Tabela 1 - Estatística de acidentes do trabalho em Santa Catarina, segundo o objeto causador (INSS/SC, 1997).

\begin{tabular}{|l|c|c|}
\hline Objeto Causador & $\begin{array}{c}\text { Número de } \\
\text { Acidentes }\end{array}$ & $\mathbf{\%}$ \\
\hline Queda de peso sobre o corpo & 437 & 10,63 \\
\hline Serra* & 223 & 5,42 \\
\hline Deslocar peso (erguer, carregar, puxar) & 216 & 5,25 \\
\hline Ferramentas manuais não motorizadas* & 194 & 4,72 \\
\hline Perda de equilíbrio, escorregão, traspés sem queda & 176 & 4,28 \\
\hline Aprisionamento (apertado, colhido, esmagado, dentro de ou entre objetos) & 174 & 4,23 \\
\hline Transporte terrestre motorizado (condutor)* & 174 & 4,23 \\
\hline Objeto cortante* & 161 & 3,92 \\
\hline Outras perdas, choques, impactos não constantes desta relação & 158 & 3,84 \\
\hline Objeto penetrante & 118 & 2,87 \\
\hline Queda do mesmo nível & 115 & 2,8 \\
\hline Corpo estranho ocular & 107 & 2,6 \\
\hline Outras máquinas e aparelhos não constantes desta relação* & 104 & 2,53 \\
\hline Quedas, choques, impactos não especificados ou inconclusivos & 95 & 2,31 \\
\hline Queda com diferença de nível (escada) & 87 & 2,12 \\
\hline Choque contra objetos ou pessoas presentes no ambiente de trabalho & 84 & 2,04 \\
\hline Máquinas de polir, jatear, afiar (esmeril, lixadeira...)* & 82 & 1,99 \\
\hline Máquina ou mecanismo para deslocar cargas (guincho, elevador de carga & 72 & 1,75 \\
\hline etc)* & & \\
\hline Sistema de transmissão (correias, polias etc.)* & 66 & 1,61 \\
\hline Queda com diferença de nível (veículo) & 66 & 1,61 \\
\hline Máquinas e aparelhos não especificados ou inconclusivos* & 64 & 1,56 \\
\hline Inconclusivo & 62 & 1,51 \\
\hline Transporte terrestre não motorizado (condutor)* & 58 & 1,41 \\
\hline Máquinas de corte (guilhotina, fatiador etc)* & 55 & 1,34 \\
\hline Objeto projetado sobre o corpo & 51 & 1,24 \\
\hline OUTROS & 912 & 22,19 \\
\hline TOTAL GERAL & 4111 & 100 \\
\hline & & \\
\hline
\end{tabular}

Embora os dados da Tabela 1 sejam pouco detalhados e quase um quarto dos acidentes sejam atribuídos a "outros" objetos causadores, pode-se obter dela a informação de que cerca de 30\% dos acidentes ocorreu na interação do trabalhador com seus meios de produção (veja itens assinalados com *). A segunda maior causa de acidentes está associada ao uso de serras elétricas para madeira e para metais e 
discos de corte para pisos cerâmicos, utilizados nas indústrias madeireiras e moveleiras, na indústria mecânica e na construção civil, respectivamente. Os acidentes com serras ocorrem, principalmente, devido à falta de alternativas seguras de projeto para o corte de materiais e/ou devido à falta de proteção adequada para o operador, fato que se repete para outras máquinas de corte, sendo as conseqüências cortes e mutilações nos dedos e nas mãos. Sistemas de transmissão sem proteção adequada permitem acesso dos operadores quando em funcionamento, ocasionando o esmagamento de partes do corpo do operador. Alguns equipamentos, por exemplo, esmeris, lixadeiras e serras, quando desprovidos de proteção, podem lançar fragmentos contra os operadores, podendo atingir os olhos, quando estes não usarem equipamentos de proteção individual. Máquinas de polir, jatear e afiar - quando do contato do operador com o rebolo ou o objeto abrasivo - causam a laceração de partes do corpo, quando também estas estiverem desprovidas de proteção.

Como cerca de três quartos dos acidentes na Tabela 1 pode ser associada com algum produto industrializado, faz sentido perguntar se o projeto destes produtos não foi deficiente, se a escolha de princípios de funcionamento não deixou de considerar aspectos ergonômicos, se a "economia" de um dispositivo de proteção não foi uma má decisão? A resposta a esta pergunta é sim, na medida em que a maioria dos acidentes com os meios de produção mencionados no parágrafo anterior poderia ter sido evitada pelo provimento de uma proteção adequada neles. Tais dispositivos de proteção devem ser integrados ao produto desde o seu projeto.

Em outros produtos, as interações com o usuário são mais complexas e perigosas, significando um desafio maior para o projetista, e demandando a consideração explícita de aspectos ergonômicos no projeto. A primeira medida efetiva neste sentido é uma boa distribuição de tarefas entre produto e usuário para garantir uma interação adequada entre eles na fase de uso.

Alguns acidentes, aparentemente causados pelo mau uso de produtos, quando devidamente investigados, podem estar diretamente relacionados com as características deles. No dia 25 de novembro de 1990, num hotel de Santos/SP, uma empregada retirava roupas já lavadas de uma lavadora industrial. Num dado momento, a lavadora entrou em funcionamento na fase de centrifugação e a roupa aprisionou o membro superior esquerdo da empregada, causando-lhe as seguintes 
lesões: amputação do membro superior esquerdo na altura do ombro, fratura do antebraço direito e múltiplas escoriações pelo corpo. As causas do acionamento não foram determinadas, podendo ser inclusive devido ao mau uso do equipamento, porém o fator determinante para a ocorrência do acidente foi a falta de dispositivo que impedisse o funcionamento da máquina com a porta aberta (Fundacentro, 1991).

Segundo a Fundacentro, na região de Criciúma, a introdução da mecanização na mineração subterrânea de carvão aumentou os riscos de acidentes. Nas minas que utilizam processos manuais de extração $10 \%$ dos trabalhadores haviam se acidentado no período de um ano, enquanto nas minas com extração mecanizada o índice chegou a $21,5 \%$. A necessidade de maior espaço para acomodar os equipamentos aumentou o número de acidentes, nos quais ocorrem principalmente a queda do teto ou das paredes laterais das galerias. Além do risco de acidente, aumentaram também o nível de pressão sonora, a taxa de liberação de gás metano e a concentração de poeira de carvão no ar, sendo esses fatores causadores de surdez, explosões e pneumoconioses, respectivamente (ABPA, 1998).

$\mathrm{Na}$ indústria da construção civil, o uso de elevadores de carga tem sido mencionado como responsável por grande parte dos acidentes fatais. Entre os principais fatores mencionados cita-se: a falta de qualificação dos operários, o não uso de dispositivos de segurança, a falta de manutenção preventiva, a montagem incorreta da torre, o transporte simultâneo de pessoas e cargas, o excesso de peso, cabos de aço em condições precárias e uso de arames na amarração das torres. Um dos mais freqüentes tipos de acidentes fatais ocorre devido à falta de dispositivos que informem a localização do elevador, fazendo com que os operários coloquem a cabeça dentro da torre para ver se o elevador está chegando (ABPA, 1999), o que obviamente é um erro de projeto.

No ano de 1984, na região sisaleira da Bahia, havia cerca de 300 trabalhadores mutilados devido ao uso de máquina desfibradora do sisal. As mutilações ocorrem quando as mãos ou os braços dos operadores entram pela área de alimentação, sendo esmagados pelas engrenagens. Isso ocorre, principalmente, com máquinas de pequeno porte, que processam entre 150 e $300 \mathrm{~kg}$ por dia e que têm apenas uma entrada para o sisal, que é também o local por onde a planta é retirada, 
após passar pelo rolo de descorticagem. As vezes, quando a planta está sendo retirada, as fibras prendem no rolo, puxando a mão do operador, mutilando-o. $\mathrm{Na}$ região sisaleira da Paraíba, as máquinas utilizadas possuem uma entrada e uma saída independentes, processando o sisal sem risco de mutilações (Fundacentro, 1990). A constatação é evidente: a utilização de outros conceitos no projeto de produtos, diminui, consideravelmente, o risco de acidentes.

Outra fonte importante de dados sobre acidentes é a estatística do Ministério da Aeronáutica (Ministério da Aeronáutica, 1998). Na Figura 1 está a distribuição dos fatores contribuintes nos acidentes aeronáuticos da aviação geral, ocorridos entre 1987 e 1997 no Brasil. Como pode haver a ocorrência concomitante de vários fatores num acidente, o somatório dos percentuais é maior que $100 \%$. As principais categorias de fatores contribuintes apontadas são:

- Fator Operacional: desempenho do homem nas atividades relacionadas ao vôo. Ex.: respeito aos procedimentos de vôo, conhecimento da aeronave pela tripulação;

- Fator Humano: aspectos fisiológicos e psicológicos do tripulante. Ex.: fadiga, sono, doenças;

- Fator Material: a aeronave nos aspectos de projeto, fabricação e manuseio do material. Ex.: fadiga dos materiais da aeronave, projeto deficiente, erros de fabricação e montagem da aeronave.

Observando a Figura 1, percebe-se uma grande influência dos fatores operacionais nas causas dos acidentes. Na Tabela 2 estão os percentuais de ocorrência dos diversos tipos de fatores operacionais.

Tabela 2 - Percentual dos diversos tipos de fatores operacionais contribuintes em acidentes da aviação geral, no período de 1987 a 1997 (Ministério da Aeronáutica, 1998)

\begin{tabular}{|l|c|}
\hline Descrição do Fator Operacional & Percentual de Ocorrência \\
\hline Defeito na aplicação de comando & $20,8 \%$ \\
\hline Imprudência do tripulante & $21,4 \%$ \\
\hline Defeito de supervisão & $32,3 \%$ \\
\hline Defeito de planejamento & $37,1 \%$ \\
\hline Defeito de julgamento & $45,1 \%$ \\
\hline
\end{tabular}




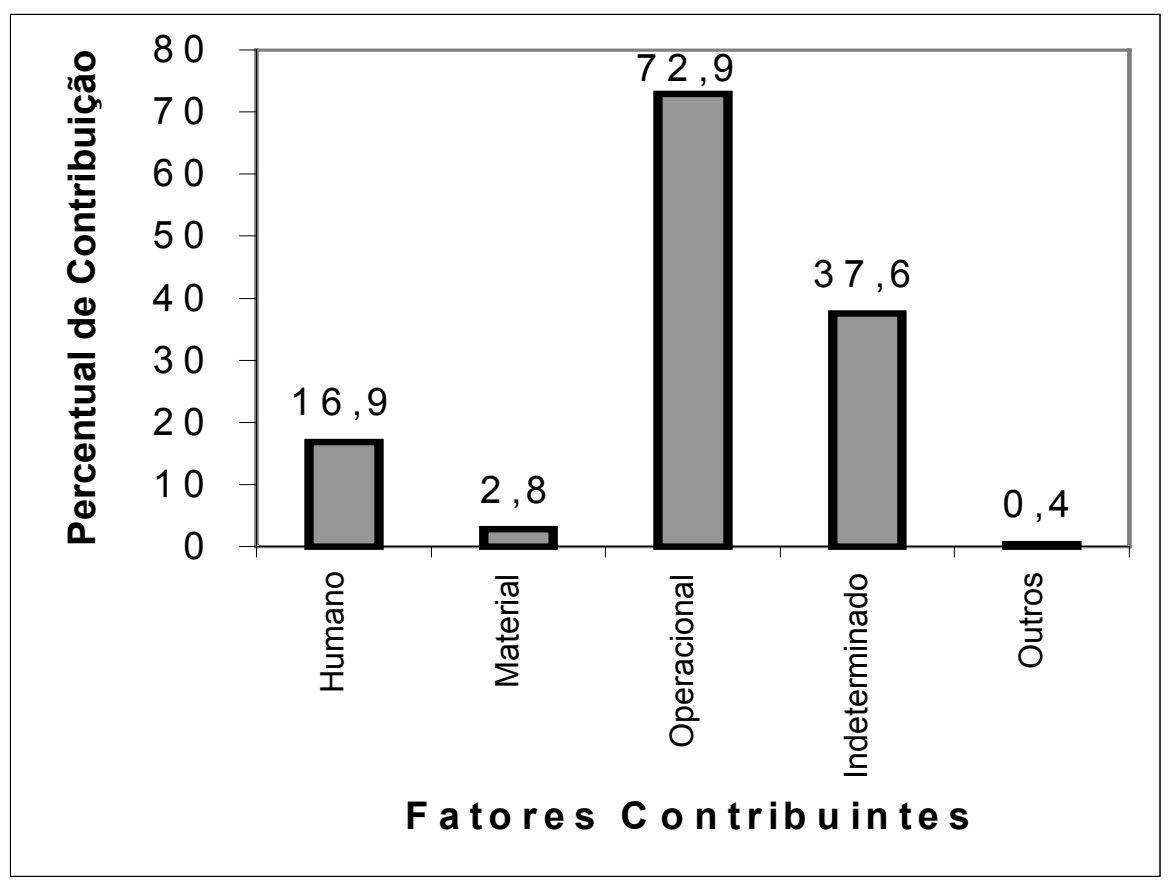

Figura 1 - Fatores contribuintes de acidentes da aviação geral, no período de 1987 a 1997 (Ministério da Aeronáutica, 1998)

Para melhor compreender a participação de fatores operacionais em um acidente, convém analisar o acidente aeronáutico ocorrido no dia 31 de outubro de 1996, com a aeronave de matrícula PT-MRK de propriedade da TAM, no qual faleceram oitenta e nove passageiros, seis tripulantes e quatro pessoas que se encontravam no local da queda.

Durante a decolagem, logo após sair do solo, a tripulação foi surpreendida por um fato anormal: o recuo do manete de aceleração do motor direito. Na tentativa de corrigir a anormalidade, a tripulação tentou restabelecer a velocidade no referido motor, reposicionando o manete. A partir daí houve uma seqüência de erros: $\mathrm{O}$ fato anormal que refletiu no recuo do manete era, na verdade, o acionamento do reversor do motor direito (um dispositivo utilizado para frear a aeronave durante o pouso), que se fechou e abriu, aleatoriamente, várias vezes, devido a um problema elétrico. Este defeito não pode ser informado pela instrumentação da aeronave, pois o sistema de indicação do reversor é inibido, quando a velocidade está acima de $148 \mathrm{~km} / \mathrm{h}$ e a aeronave está abaixo de 304 metros de altura, situação em que a aeronave se encontrava e, curiosamente, esta é a situação na qual essa informação é mais 
necessária. Por isso, não houve avisos sonoros ou luminosos, fazendo com que a tripulação interpretasse o problema erroneamente (Penteado, 1998). Num dado momento, devido ao recuo do manete do motor direito, também houve o recuo do manete do motor esquerdo, desacelerando a aeronave. Os tripulantes tomaram a iniciativa de reposicionar o manete para acelerar novamente a aeronave, o que é um procedimento errado, pois durante a decolagem qualquer ação corretiva abaixo da altura de 122 metros não é recomendável. A atitude correta seria recolher o trem de pouso e acionar o piloto automático. A atitude de reposicionamento do manete resultou no rompimento do cabo do manete. A aeronave derivou à direita, colidiu com edificações, projetou-se ao solo, incendiando-se com perda total.

Como fatores contribuintes do acidente foram apontados (Penteado, 1998):

- a pouca experiência do co-piloto neste tipo de aeronave, somente 230 horas de vôo (fator operacional). O piloto, porém, tinha 2.392 horas de vôo neste tipo de aeronave;

- a falta de informação, instruções e prática para o reconhecimento da anormalidade;

- o procedimento errôneo da tripulação (fator operacional). Em simulador de vôo, o treinamento do procedimento para corrigir o acionamento do reversor na decolagem foi abandonado pela empresa operadora, em virtude de carta do fabricante, datada de 28 de junho de 1995, em que este considera tal treinamento desnecessário, devido à pequena probabilidade de ocorrência deste tipo de problema;

- a falta de avisos discriminadores da falha;

- a falsa interpretação do problema por parte da tripulação e o julgamento deficiente da tripulação (fator operacional);

- o acionamento do reversor ocorreu como conseqüência de uma falha num relê, devido a fusão dos contatos, impedindo o travamento do reversor para o vôo. Segundo o diagrama do modo de falha feito para esse sistema, com aeronaves semelhantes, a probabilidade de acionamento dos reversores é da ordem de $10^{-6}$, o que não satisfaz os requisitos de aeronavegabilidade. Em testes posteriores ao acidente, com aeronaves semelhantes, os travadores do reversor apresentaram 
desempenho inferior ao mínimo aceitável, para garantir a segurança e a confiabilidade do sistema;

- a não existência de condição de visualização do problema durante a inspeção externa da aeronave, no solo.

Alguns fatores operacionais apontados como contribuintes para a queda da aeronave podem ser refutados com facilidade, como o procedimento errôneo da tripulação e a falta de experiência da tripulação, visto que o piloto era experiente. O procedimento da tripulação não pode ser considerado errôneo, pois desconhecia o que estava ocorrendo por falta de informação. Além disso, aponta-se como erro da tripulação o reposicionamento do manete, pois qualquer ação corretiva na decolagem é não recomendável. Ser não recomendável não significa ser proibida. Neste caso, os fatores operacionais são, na verdade, conseqüência do projeto deficiente da aeronave. $\mathrm{O}$ projeto deficiente possibilitou, num primeiro momento, que a falha de um único componente colocasse em risco a segurança do vôo. Num segundo momento, possibilitou que os fatos observados pela tripulação induzissem-na ao erro. O acidente ocorreu devido ao projeto deficiente da aeronave, sem qualquer sinal ou informação específica da ocorrência do problema para a tripulação.

Outra fonte estatística importante é o relatório de acidentes da Polícia Rodoviária Federal de Santa Catarina - PRF/SC (PRF/SC, 1997). Neles são apontadas causas únicas para os acidentes e apenas uma pequena parcela deles é atribuída a defeitos mecânicos do produto automóvel e a defeitos na pista (ver Tabela 3). Ao se apontar para o usuário como "causador" de grande parcela dos acidentes de trânsito vale lembrar que, quando se projeta um produto, deve-se distribuir entre usuário e ele as tarefas ou funções que cada um deverá executar e que o usuário, por suas limitações humanas, nem sempre consegue executar bem as funções a ele atribuídas, por exemplo, por cansaço, por perda gradativa de capacidades e habilidades com a idade, por doenças e acidentes e até mesmo por dificuldades de concentração em ocasião de estresse elevado. Quando as limitações humanas não forem consideradas satisfatoriamente no projeto de um produto, tem-se um projeto deficiente. 
Tabela 3 - Estatísticas de acidentes de trânsito em Santa Catarina

(PRF/SC, 1997)

\begin{tabular}{|l|c|c|}
\hline Causas Prováveis & $\begin{array}{c}\text { Número de } \\
\text { Acidentes }\end{array}$ & $\mathbf{\%}$ \\
\hline Não manter distância & 2135 & 29,35 \\
\hline Desrespeito à preferencial & 1950 & 26,81 \\
\hline Excesso de velocidade & 1022 & 14,05 \\
\hline Ultrapassagem forçada & 688 & 9,46 \\
\hline Imprudência pedestre/ciclista & 416 & 5,72 \\
\hline Dormir ao volante & 405 & 5,57 \\
\hline Defeito mecânico & 127 & 1,74 \\
\hline Animal solto na pista & 87 & 1,19 \\
\hline Dirigir embriagado & 14 & 0,19 \\
\hline Defeito na pista & 5 & 0,07 \\
\hline Outros & 439 & 6,03 \\
\hline TOTAL & 7274 & 100 \\
\hline
\end{tabular}

Para exemplificar como um projeto deficiente pode provocar vítimas fatais, vale recordar o acidente de automóvel ocorrido em 19 de abril de 1994. Um automóvel Mitsubishi Eclipse CL vitimou fatalmente o acompanhante Dener Augusto de Sousa. O acidente se deu por impacto contra uma árvore, no qual o veículo desacelerou de $64 \mathrm{~km} / \mathrm{h}$ até $0 \mathrm{~km} / \mathrm{h}$ em apenas $90 \mathrm{~cm}$ de curso, gastando para isso 0,1 segundo (Florenzo et al., 1994). Neste acidente há um dispositivo de segurança em jogo: o cinto de segurança. Criado para diminuir lesões corporais aos ocupantes de automóveis, a sua má utilização foi a causa da fatalidade de Dener. O automóvel em questão era dotado de dois tipos de cintos de segurança para os ocupantes dianteiros: os cintos pélvicos e os diagonais. Nesse caso, os ocupantes do automóvel não utilizavam os cintos pélvicos, apenas os diagonais. Por isso, estiveram sujeitos ao efeito pêndulo, comum quando se utiliza este tipo de cinto de segurança (Florenzo et al., 1994). No momento do impacto, o corpo é lançado para frente pela força de inércia. A parte inferior do corpo, estando livre, faz o corpo escorregar violentamente para frente, ficando o usuário do cinto preso a ele. Isso pode provocar lesões na região peitoral e na porção anterior do pescoço.

A morte de Dener, por lesões na altura do pescoço, ocorreu devido a três fatores principais: a falta do cinto pélvico, a posição do assento inadequada (assento reclinado) e o efeito pêndulo (Florenzo et al., 1994). Isso demonstra que, mesmo um dispositivo de segurança, quando mal utilizado pode levar à fatalidade. Essa forma incorreta de utilização não deveria ser possível na prática e suprimida no projeto. 


\section{CAUSAS DE ACIDENTES}

A palavra acidente está ligada à idéia de acaso ou imprevisto. Nas primeiras discussões sobre acidentes de trabalho, estes foram associados à "casualidade" ou "fatalidade", sendo considerados conseqüência natural e irremediável das atividades humanas. Dessa concepção se originaram o conceito de "risco profissional" e as ações de caráter reparatório ou compensatório, visando limitar a gravidade das conseqüências dos acidentes, em vez de eliminá-los. Essa visão influenciou e hoje ainda é influenciada pela política oficial e legislações específicas sobre acidentes de trabalho. A visão fatalista sobre acidentes de trabalho é estéril em si mesma, pois ignora a gênese do acidente de trabalho, negando qualquer formulação científica e concreta sobre ele (Lima, 1985).

Buscando compreender como e por quê os acidentes ocorrem, principalmente aqueles relacionados ao trabalho, foram formuladas diversas teorias de acidentes de trabalho, classificadas em mono e multicausais. As teorias monocausais procuram uma causa única e fundamental para a ocorrência do acidente, presente no indivíduo ou no meio que o cerca. Nelas há três abordagens: a culpabilidade, a pré-disposição aos acidentes e a acidentabilidade. Estas teorias foram consideradas inconsistentes, devido à ocorrência de acidentes sem a participação de ações incorretas (Vidal, 1983), à inconsistência metodológica, à impossibilidade de explicar grande parte deles (Iida, 1991).

As teorias multicausais se consolidaram na década de 60 e procuram a coexistência de várias causas "diretas" ou "indiretas" (Macmahon et al., 1975), que formam uma cadeia de eventos, culminando na ocorrência do acidente. As teorias de Heinrich (Heinrich, 1959), a tríade ecológica (Leavell, 1976) e a teoria dos portadores de perigos (citada em Sell, 1990) são exemplos de teorias multicausais. As teorias mono e multicausais são insuficientes e incompletas para a compreensão da ocorrência de acidentes, por não considerarem fatores sociais neste evento. Heinrich (1959) classificou as possíveis causas em fatores técnicos e fatores humanos. Nessa concepção, traços negativos da personalidade, adquiridos por influências hereditárias do meio familiar e social, levam o homem a cometer falhas ou atos inseguros. Como é bastante difícil modificar traços negativos da 
personalidade de trabalhadores, para assim eliminar os atos inseguros, esta concepção tem uma baixa eficiência (Lima, 1985). Devido ao interesse de se encontrar um responsável pelo acidente, normalmente, dá-se maior importância aos atos inseguros do que às condições inseguras. Culpar condições inseguras significa ter de realizar ações efetivas de correção do ambiente de trabalho e do equipamento. Então fica mais fácil tomar medidas de prevenção para atos inseguros: "educação" do trabalhador e utilização de equipamentos de proteção individual, quase sempre incômodos e eficazes apenas na prevenção de lesões, passam a ser ações correntes (Lima, 1985).

As teorias da tríade ecológica e dos portadores de perigos analisam as interações entre objeto e pessoa na busca de causas de acidentes. Há acidentes causados pela fadiga de um componente do produto, sem o envolvimento direto de pessoas no uso. Em outros casos, atos inseguros podem ser facilmente apontados. Porém, se um ato inseguro pode provocar acidentes com um produto, é porque o produto possui características que permitem atos inseguros ou permitem que atos inseguros resultem em acidentes. Então, a potencialidade de ocorrência de acidentes está, principalmente, associada aos perigos presentes nos produtos.

O erro humano, apontado como a origem dos atos inseguros, é uma realidade não restrita à fase de uso do produto. Também em áreas como projeto, manufatura, manutenção e administração (Clarke, 1998) são cometidos erros. Ele consiste num desvio em relação a procedimentos pré-estabelecidos, podendo estar subordinado a situações que o propiciam, como características perigosas em produtos. Estudos de Hansen (1989) demonstraram que eles ocorrem em tarefas mais perigosas e/ou quando o operador não compreende bem o funcionamento da máquina que utiliza. Em outras palavras: não são trabalhadores os grandes responsáveis pela maioria dos acidentes, mas sim as ocupações ou tarefas e as condições perigosas relacionadas ao trabalho deles. Dougherty (1997) afirma que o erro humano irá ocorrer e distribuir-se de acordo com a situação, pois esta pode sugerir ou induzir a inclusão de atitudes erradas pelo indivíduo ou ainda interferir no tempo de resposta, comprometendo o desempenho humano. Além disso, o ambiente pode induzir ao erro devido à ocorrência de, por exemplo, chuva, neblina, neve ou à presença de insetos e defeitos nas pistas de rolagem. Erros nestas circunstâncias são, erradamente, considerados 
erros do usuário. Então, se o projeto de produtos e as condições ambientais podem induzir a erros, à distração, à fadiga pela presença de perigos e não prevenção do risco com dispositivos de segurança, por exemplo, esses problemas também podem ser prevenidos ou mitigados com bons projetos e com manutenção de boas condições ambientais.

$\mathrm{Na}$ verdade, só se pode falar em erro humano quando, num produto, os princípios ergonômicos tiverem sido aplicados adequadamente e o usuário tiver sido devidamente instruído e treinado em condições realísticas, respeitando-se as capacidades e limitações humanas (Nelson \& Associates, 2000) e mesmo assim este tiver um comportamento diverso do padrão esperado. Como o consumidor de bens de consumo não recebe treinamento, o projeto destes produtos deve garantir alta segurança intrínseca, pois a simples desculpa do erro humano não procede neste caso. Mesmo para Tiffin \& McCormick (1975), que afirmam que a tendência a erros é uma característica inerente ao ser humano, o indivíduo pode não ser a fonte de erros e acidentes. A natureza das atividades do trabalho, o projeto do equipamento, os métodos de trabalho, o ambiente e outras variáveis podem exercer influência sobre a freqüência e a natureza dos erros e acidentes. Esses autores consideram que as fontes de erros podem ser atribuídas a fatores individuais e de situação ou à combinação destes. Hammer (1993) associa a ocorrência de acidentes às características perigosas ou perigos existentes nos produtos, causados principalmente pelo projeto deficiente, por defeitos de manufatura ou por características inerentes ao produto ou a materiais utilizados.

\section{A GÊNESE DE ACIDENTES COM PRODUTOS}

Na literatura brasileira há uma certa confusão entre risco e perigo, sendo às vezes, trocados. Sell (1990) conceitua perigo como uma energia danificadora, a qual, se ativada, pode provocar lesões e/ou danos materiais. Na verdade trata-se de um estado potencial. Uma máquina pode apresentar um perigo inerente ao seu funcionamento, porém se forem tomados os devidos cuidados ou medidas de proteção, o risco oferecido por ela será mínimo. Isso porque risco pode ser concebido apenas quando existir um perigo e alguma coisa de valor ou pessoas estiverem em 
contato com ele (Dieter, 1983). O risco decorre da exposição ao perigo e pode resultar em acidentes, se houver um evento deflagrador, como a inclusão de uma ação pelo usuário, que não estava programada.

Sell (1990) define acidente como uma colisão repentina e involuntária entre pessoa e objeto, resultando em danos materiais e/ou lesões. Um acidente se diferencia de uma doença ocupacional por ser repentino enquanto a doença ocupacional requer um prazo maior para ser adquirida. Como dano entende-se perda física, funcional ou econômica (Dieter, 1983), tais como lesões a pessoas, prejuízos a equipamentos ou estruturas, perdas de materiais de um processo ou redução da capacidade de desempenho da função envolvida. Baseado nestes conceitos criou-se um fluxograma para esquematizar a ocorrência de um acidente, apresentado na Figura 2, alicerçado nos pressupostos:

- Pré-existência de perigo no produto, com potencial de afetar pessoas ou objetos. É o início do processo do acidente. Esse perigo é, normalmente, decorrente de determinadas características apresentadas pelo produto, tais como eletricidade, radiação, alta temperatura, partes cortantes e componentes girantes com inércia elevada;

- Pela exposição de pessoas ou objetos ao perigo é dada uma condição de risco. Como exemplo de condição de risco pode-se citar um perigo sem proteção (por exemplo, uma correia, uma polia, uma serra), expondo o operador ao perigo;

- O acidente exige a ocorrência de algum evento deflagrador, que possibilite a sua manifestação. Por exemplo, uma serra circular para madeira (produto com perigo inerente), teve sua proteção retirada para facilitar o corte de madeiras (condição de risco). Durante a execução da tarefa o operador, involuntariamente, colocou a mão na serra, o que caracteriza um acidente, independente de haver ou não lesão. Neste caso, o evento deflagrador foi a colocação involuntária da mão na serra.

- Para que ocorram danos, é necessário que pessoas ou objetos sejam atingidos na ocorrência do acidente. No exemplo anterior, o dano seria a lesão na mão do operador. 


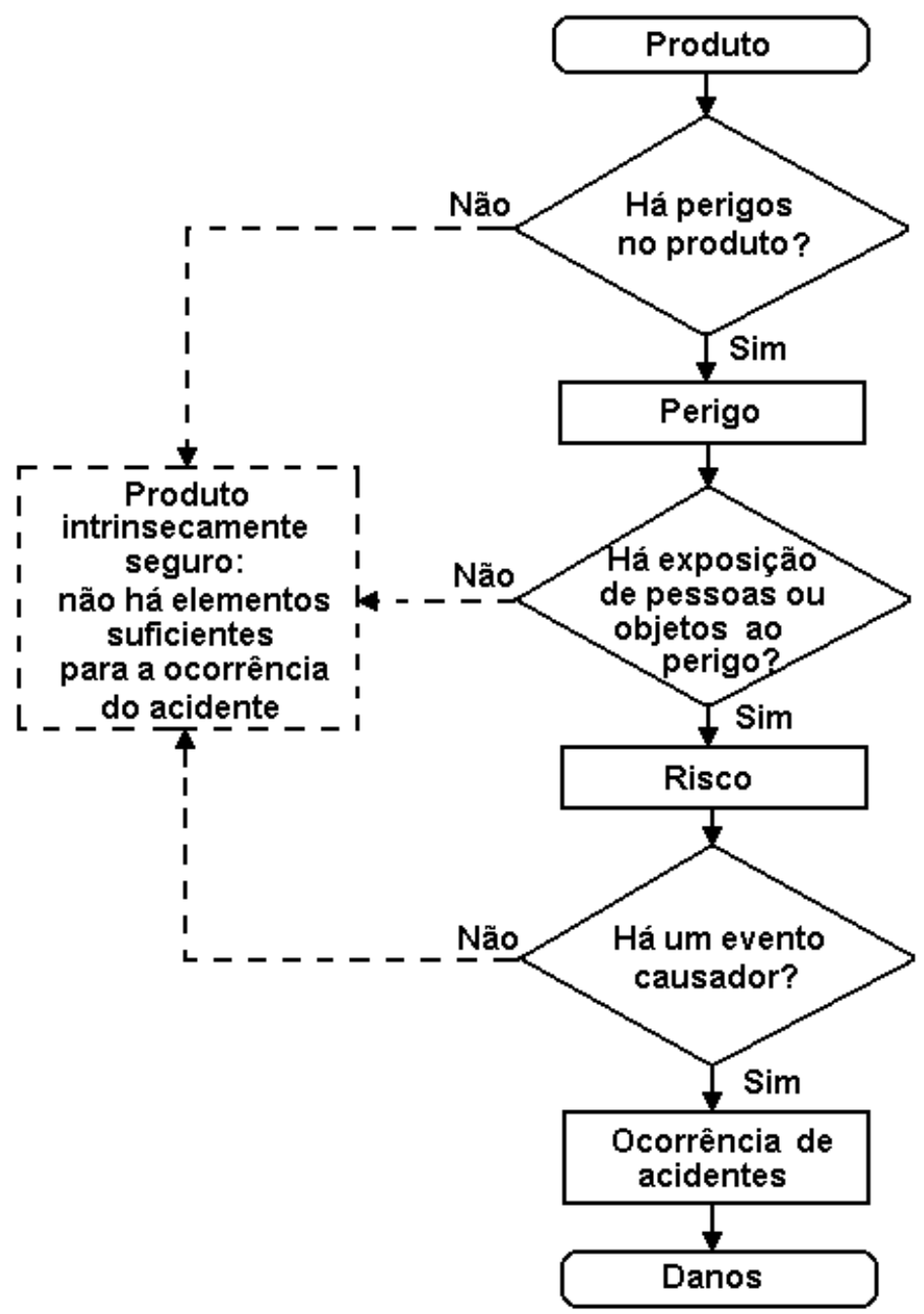

Figura 2 - Fluxograma de um acidente, com seus principais elementos

Na Figura 2 foi utilizada a expressão "produto intrinsecamente seguro". Essa seria a situação ideal mas é utópica, pois o simples fato de um produto existir fisicamente e ocupar lugar no espaço permite que pessoas colidam com ele. Como a diversidade de combinações entre perigos e possibilidades de interação entre pessoas e objetos com partes de produtos, que venham a ser perigos em certas circunstâncias, é grande, não há como garantir segurança absoluta e por conseqüência, como projetar produtos totalmente seguros. Contudo, o risco deve ser minimizado até o chamado risco tecnicamente e socialmente aceitável, um critério sócio-técnico. 


\section{CONCLUSÃO}

Considerando as estatísticas e relatórios de acidentes de trânsito e de trabalho, observa-se que estes estão freqüentemente associados com produtos perigosos ou que apresentam características perigosas com potencial de gerar acidentes. As deficiências dos produtos aliadas ao despreparo dos usuários (usuários não são treinados adequadamente, não se tem o hábito de ler os manuais e, muitas vezes, estes também não esclarecem as dúvidas quanto à utilização correta do produto) continuam a causar um grande número de acidentes com produtos, sejam eles eletrodomésticos, máquinas industriais, automóveis ou ferramentas.

Com o estudo das teorias de acidentes de trabalho observou-se que elas evoluíram de uma visão em que o trabalhador era sempre o culpado pelo acidente, até uma que admite a coexistência de diversas causas para os acidentes, aliviando a carga psíquica de trabalhadores enquanto operadores de máquinas diversas. Mas se se considerar como Nelson \& Associates (2000) apenas o verdadeiro erro humano e os elementos relacionados com a ocorrência de acidentes, observa-se que a contribuição humana é também uma conseqüência da situação, do contexto da tarefa e/ou das características do produto. Esta visão mais moderna, na qual nem sempre o usuário é responsável pelo acidente, demanda a incorporação de conhecimentos e dados da Ergonomia nos projetos. A melhor maneira de evitar acidentes é tornar o produto tão seguro quanto possível, visto que nem sempre pessoas treinadas ou que compreendem bem o produto utilizá-lo-ão na prática. Há de se considerar ainda que, também pessoas treinadas poderão deixar de seguir os procedimentos corretos, especialmente quando estes forem complexos. A definição dos elementos relacionados com acidentes possibilitou determinar uma seqüência lógica para a ocorrência dos acidentes. Observando o fluxograma anterior (Figura 2), pode-se afirmar que os perigos decorrentes de características dos produtos propiciam a ocorrência de acidentes. Nota-se que, com a ausência de perigos, não se tem a geração do acidente. Para garantir que um produto seja inerentemente seguro, tornase necessário eliminar perigos e, quando isso não é possível - não se pode cortar sem faca afiada ou serra - deve-se evitar as possibilidades de interação de pessoas com o perigo, reduzindo assim o risco. 


\section{REFERÊNCIAS BIBLIOGRÁFICAS}

(ABPA, 1998) Associação Brasileira para Prevenção de Acidentes. Tecnologia moderna não reduz riscos. Revista SOS. 200, 5 bimestre de 1998. pg. 20. (ABPA, 1999) Associação Brasileira para Prevenção de Acidentes. Acidentes com elevadores de carga. Revista SOS. 202, $1^{\circ}$ bimestre de 1999. pg. 12-13.

(Clarke, 1998) Clarke, D.M. The human face of risk. Nuclear Engineer, jul-ago 1998, vol. 39, nº 4, pg 115-119.

(Dieter, 1983) Dieter, George E. Engineering design: a materials and processing approach. New York: McGraw-Hill, 1983.

(Dougherty, 1997) Dougherty, E.M. Is human failure a stochastic process? Reliability Engineering and System Safety, 1997, nº 55, pg 209-215.

(Florenzo et al., 1994) Florenzo, Valdir; Martello Filho, Ventura Raphael. Parecer Técnico e Diagnose sobre Acidentes de Trânsito. São Paulo: Dynamics, maio de 1994.

(Fundacentro, 1990) Fundação Jorge Duprat Figueiredo de Segurança e Medicina do Trabalho. Nova máquina sisaleira é projeto da Fundacentro. Fundacentro: atualidades em prevenção de acidentes. vol. 21, 247, jul. 1990, p.3-4.

(Fundacentro, 1991) Fundação Jorge Duprat Figueiredo de Segurança e Medicina do Trabalho. Relatório investiga acidente ocorrido em lavanderia de hotel. Fundacentro: atualidades em prevenção de acidentes. vol. 22, 256, jun. 1991, p.4-5.

(Hammer, 1993) Hammer, Willie. Product Safety Management and Engineering. EUA: ASSE, 1993. 2. Ed.

(Hansen, 1989) Hansen, P.C. A causal model of the relationship among accidents, biodata, personality, and cognitive factors. Journal of Applied Psychology 1989, vol. 74, № 1 , pg. 81-90.

(Heinrich, 1959) Heinrich, H.W. Industrial Accident Prevention. New York:

McGraw-Hill, 1959. 4. Ed.

(Iida, 1991) Iida, Itiro. Novas Abordagens em Segurança do Trabalho. Rio de Janeiro: Produção, mar. 1991. V.1 nº 2. Pg. 63-73. 
(INSS/SC, 1997) Instituto Nacional de Seguro Social de Santa Catarina; DATAPREV/SC. Comunicação de Acidente do Trabalho. Relatório 1996. Florianópolis, 1997.

(Leavell, 1976) Leavell, Hugh; Clark, E. G. Medicina Preventiva. São Paulo: McGraw-Hill, 1976.

(Lima, 1985) Lima, Francisco de Paula Antunes. Contribuição à Análise da Insegurança no Trabalho e do Projeto de Máquinas mais Seguras. Dissertação de Mestrado. Universidade Federal de Santa Catarina, Centro Tecnológico, Departamento de Engenharia Mecânica. Florianópolis, SC, 180 págs., agosto de 1985.

(Macmahon et al., 1975) Macmahon, B.; Pugh, T.F. Princípios y Métodos de Epidemiologia. México: Prensa Mexicana, 1975.

(Ministério da Aeronáutica, 1998) Ministério da Aeronáutica. Estatísticas de

Acidentes Aeronáuticos do Período 1987-1997. Rio de Janeiro: CENIPA, 1998.

(Nelson \& Associates, 2000) Nelson \& Associates. Core Principles of Safety Engineering and the Cardinal Rules of Hazard Control. Capturado em 02 de mar. 2000. Online. Disponível na Internet http://www.hazardcontrol.com/coreprinciples.html.

(OIT, 1993) Organização Internacional do Trabalho. Anuário de Estatísticas do Trabalho. São Paulo: OIT, 1993.

(Penteado, 1998) Penteado, Paulo Albano de Godoy - Cel.Av. Carta nº06/CH/98.

Brasília: Centro de Investigação e Prevenção de Acidentes Aeronáuticos CENIPA/Ministério da Aeronáutica, 1998.

(PRF/SC, 1997) Polícia Rodoviária Federal de Santa Catarina. Relatório de Acidentes de Trânsito 1995/1996. Florianópolis, 1997.

(Sell, 1990) Sell, Ingeborg. A contribuição da ergonomia na segurança do trabalho.

Revista Brasileira de Saúde Ocupacional. Ministério do Trabalho e Previdência Social. Fundacentro. Abr/Mai/Jun. 1990. Pg 44-49. N 70, V. 18.

(Tiffin et al., 1975) Tiffin, J.; McCormick, E.J. Psicologia Industrial. São Paulo, EPU, 1975. 
(Vidal, 1983) Vidal, Mário. Evolução Conceitual da Noção de Acidente do Trabalho. João Pessoa, 1983. 